\title{
ALLELIC POLYMORPHISM OF crtRB1 AND LcyE GENES RELATED TO THE $\beta$-CAROTENE CONTENT IN VIETNAMESE TRADITIONAL MAIZE ACCESSIONS
}

\author{
Nguyen Duc Thanh", Nguyen Thi Lan, Ho Thi Huong \\ Institute of Biotechnology, VAST, Vietnam
}

Received 13 May 2019, accepted 22 July 2019

\begin{abstract}
Maize is the third most important food crop after wheat and rice. Maize is used as food for more than a billion people around the world and is used as animal feed, especially, poultry. The concentration of carotenoids, especially, $\beta$-carotene in maize grains, is very low. Therefore, the study of increasing the amount of provitamin A carotenoids including $\beta$-carotene is important. In maize, different alleles of $c r t R B 1$ and $L c y E$ genes have a significant effect on $\beta$-carotene content. In this paper, we present the results of the study of allele polymorphism of these two genes related to the provitamin A carotenoid content in some traditional maize accessions collected from several regions in North and Central Highlands of Vietnam. The results showed that there were polymorphisms at the 3' and 5' ends of the crtRBI and $L c y E$ genes. Among 22 maize accessions, the proportion of favorable alleles at the 3' end of crtRB1 gene was relatively high $(5 / 22=22.73 \%)$. Similar results were obtained for alleles at the 3 ' end of the LcyE gene. Especially, there is an accession (Nep vang trang mien Bac - Northern white gold maize) that carries favorable alleles at the 3' ends of both $c r t R B 1$ and $L c y E$ genes. While all investigated maize accessions did not carry favorable alleles at the 5' end of both $\operatorname{crtRB} 1$ and $L c y E$ genes. The identification of traditional maize accessions that carry favorable alleles for increasing $\beta$-carotene content opens up potential to exploit indigenous genetic resources for genetic research as well as to develop maize varieties with high $\beta$ - carotene content.
\end{abstract}

Keywords: Zea mays L., allelic polymorphism, $\beta$-carotene, crtRB1 gene, LcyE gene, maize.

Citation: Nguyen Duc Thanh, Nguyen Thi Lan, Ho Thi Huong, 2019. Allelic polymorphism of crtRB1 and LcyE genes related to the $\beta$-carotene content in Vietnamese traditional maize accessions. Academia Journal of Biology, 41(3): 77-84. https://doi.org/10.15625/2615-9023/v41n3.13815.

*Corresponding author email: nguyenducthanh_pcg@ibt.ac.vn

(C2019 Vietnam Academy of Science and Technology (VAST) 


\section{INTRODUCTION}

Maize is the third most important food crop after wheat and rice and is consumed by more than a billion people worldwide. Besides, is also a food source for livestock, especially for poultry. Carotenoid content in maize seeds is higher than other cereal crops, but low and highly varied in maize lines. According to Harjes et al. (2008), most of the world's cultivated and consumed maize varieties contain only 0.5 to $1.5 \mu \mathrm{g} / \mathrm{g} \quad \beta$ carotene. Kurilich and Juvik (1999) used HPLC to analyze carotenoids in five sweet maize varieties, indicating that the $\beta$-carotene content ranged from 0.14 to $7.97 \mu \mathrm{g} / \mathrm{g}$ dry weight. $\beta$-carotene is a precursor of vitamin $\mathrm{A}$, which helps the body prevent vitamin $\mathrm{A}$ deficiency, preventing blindness, strengthening the immune system. Humans cannot synthesize vitamin A, so it takes nutrients from food sources (liver, fish, eggs and milk) containing vitamin A (retinol), and precursors of vitamin A from colored vegetables and fruit (carrot, papaya, pumpkin, red bell pepper, grapefruit) in the form of provitamin A carotenoids. In regions where maize is the main food source, the use of maize will lead to a deficiency of vitamin A. Vitamin A is important for eye health, protection of age-related macular degeneration, adjustment and improve the immune system and increase infection resistance (Ross, 1998; Semba, 2009, Huang et al., 2018). Vitamin A deficiency is a global health problem, making 140 to 250 million people at risk of many health problems (Harjes et al., 2008), which can lead to blindness and increase. illness as well as mortality in preschool children (WHO, 2010).

In maize, there are five genes that play an important role in the final content of provitamin A carotenoids. The first gene, PSY1, encodes phytoene synthase with two alleles related to the total carotenoid content (Fu et al., 2013a). The second gene, LcyE, encodes lycopene epsilon cyclase with four alleles, involved altering the ratio of different carotenoids in $\alpha$ - to $\beta$ - branches in the carotenoid biosynthesis pathway (Harjes et al., 2008). crtRB3 is the third gene coding for the enzyme $\alpha$-carotene hydroxylase and the fourth gene, ZEPl, controls zeaxanthin epoxidase; Both genes have been known to play a role in carotenoid metabolism (Vallabhaneni, Wurtzel, 2009; Zhou et al., 2012). The fifth gene encoding $\beta$-carotene hydroxylase enzyme (crtRBl) with three alleles has a significant impact on the change of $\beta$-carotene content in endosperm (Fu et al., 2013b). The results of Yan et al. (2010) showed the concentration of provitamin A of haplotypes with favorable alleles of crtRB15'TE and crtRB1-3'TE to be 5.2 times higher than all other haplotypes. Babu et al. (2013) reported that $\operatorname{crtRB} 1$ had a much greater effect on provitamin A content than $L c y E$. The crtRBI gene is not inherited by Mendel law, while the $L c y E$ gene is inherited by Mendel (Zunjare et al., (2017). The study of favorable alleles of the $L c y E$ gene in 13 samples of indigenous and imported maize varieties, Zunjare et al. (2018) determined that there were 8 genotypes with favorable and 5 with unfavorable alleles of $L c y E$ gene. Identifying indigenous traditional maize genotypes carrying favorable alleles for the increase in $\beta$-carotene content is important for varietal selection because in addition to increasing the content of $\beta$-carotene, indigenous traditional maize also provides additional tolerance genes and adaptation to native ecological conditions. However, the proportion of favorable alleles of $\operatorname{crtRB} 1$ and $L c y E$ genes is quite low and respectively $3.38 \%$ and $3.90 \%$ (Muthusamy et al (2015). Similar results were also reported in several studies, for example, in 210 investigated maize lines, Selvi et al. (2014) identified only one line had favorable allele of crtRB1 gene.

In the previous published paper, we examined the frequency of favorable alleles for $\beta$-carotene accumulation in some improved and imported maize varieties in Vietnam (Tran Thi Luong, Nguyen Duc Thanh, 2018). In this paper, we present the results of allele polymorphism related to the $\beta$-carotene content of $c r t R B I$ and $L c y E$ genes in local traditional maize accessions collected 
from several regions in the North and the Central Highlands, with the aim of evaluating these alleles polymorphisms and identifying maize accessions with favorable alleles to exploit indigenous genetic resources as a raw material for selecting maize varieties with high $\beta$-carotene content.

\section{MATERIALS AND METHODS}

\section{Materials}

Twenty-two accessions of local traditional maize accessions from Northern and Central Highlands provinces were provided by the
Center for Plant Resources, Vietnam Academy of Science and Technology (table 1).

The alleles of the 3' end of crtRBI gene (crtRB1- 3'TE) were analyzed by crtRB13'TE-F: 5'-ACACCACATGGACAAGTTCG -3', crtRB1-3'TE-R1: 5'-ACACTCTGGCCC ATGAACAC-3' and crtRB1-3'TE-R2: 5'-AC AGCAATACAGGGGACCAG-3' primers (Yan et al., 2010). While, the alleles of the 5' end (crtRB1-5'TE) were analyzed by crtRB15'TE-2F: 5'-TTAGAGCCTCGACCCTCTGT G-3' and crtRB1-5'TE-2R: 5'-AATCCCTTT CCATGTACGC-3' primers (Liu et al., 2015).

Table 1. Results of allelic polymorphism of $c r t R B 1$ and $L c y E$ genes by PCR with corresponding primers

\begin{tabular}{|c|c|c|c|c|c|c|c|}
\hline No. & Maize accessions & Origins & $\begin{array}{l}\text { crtRB1- } \\
\text { 3'TE-R1 }\end{array}$ & $\begin{array}{l}\text { crtRB1- } \\
\text { 3'TE-R2 }\end{array}$ & $\begin{array}{l}\text { crtRB 1- } \\
5 \text { 'TE }\end{array}$ & LcyE-3'TE & LcyE-5'TE \\
\hline 1 & $\begin{array}{l}\text { Te vang Lung } \\
\text { chang } 2\end{array}$ & $\begin{array}{l}\text { Thai Hoc, Nguyen } \\
\text { Binh, Cao Bang }\end{array}$ & $296 \mathrm{bp}$ & 543 bp & $800 \mathrm{bp}$ & $100 \mathrm{bp}$ & $280+350 b p$ \\
\hline 2 & Te vang Na Lung 1 & $\begin{array}{l}\text { Ca Thanh, Nguyen } \\
\text { Binh, Cao Bang }\end{array}$ & $296 \mathrm{bp}$ & - & - & $100 \mathrm{bp}$ & $280 \mathrm{bp}$ \\
\hline 3 & Bap cham luong & $\begin{array}{l}\text { Nam Quang, Bao } \\
\text { Lam, Cao Bang }\end{array}$ & $296 \mathrm{bp}$ & - & 800 bp & $100 \mathrm{bp}$ & $280 \mathrm{bp}$ \\
\hline 4 & Bap cham deng & $\begin{array}{l}\text { Tien Thanh, Phục } \\
\text { Hoa, Cao Bang }\end{array}$ & $296 \mathrm{bp}$ & - & - & $100 \mathrm{bp}$ & $280 \mathrm{bp}$ \\
\hline 5 & Bap cham deng & $\begin{array}{l}\text { Nam Quang, Bao } \\
\text { Lam, Cao Bang }\end{array}$ & $296 \mathrm{bp}$ & - & 800 bp & $144+100$ bp & $280 \mathrm{bp}$ \\
\hline 6 & Bap nua lai & $\begin{array}{l}\text { Nam Quang, Bảo } \\
\text { Lam, Cao Bang }\end{array}$ & $296 \mathrm{bp}$ & - & $800 \mathrm{bp}$ & $100 \mathrm{bp}$ & $280+350 \mathrm{bp}$ \\
\hline 7 & Bap cham & $\begin{array}{l}\text { Nam Quang, Bao } \\
\text { Lam, Cao Bang }\end{array}$ & $296 \mathrm{bp}$ & - & - & $144+100$ bp & $280 \mathrm{bp}$ \\
\hline 8 & Ta vang Na Leng & $\begin{array}{l}\text { Luong Ha, Na Ri, } \\
\text { Bac Kan }\end{array}$ & $296 \mathrm{bp}$ & 543 bp & 800 bp & $100 \mathrm{bp}$ & $280+350 \mathrm{bp}$ \\
\hline 9 & Te vang Lung can & $\begin{array}{l}\text { Kim } \mathrm{Hy}, \mathrm{Na} \mathrm{Ri}, \mathrm{Bac} \\
\text { Kan }\end{array}$ & $296 \mathrm{bp}$ & 543 bp & - & $100 \mathrm{bp}$ & $280 \mathrm{bp}$ \\
\hline 10 & $\begin{array}{l}\text { Nep vang Dong } \\
\text { Van }\end{array}$ & Đong Van, Ha Giang & $296 \mathrm{bp}$ & & 800 bp & $100 \mathrm{bp}$ & $280 \mathrm{bp}$ \\
\hline 11 & $\begin{array}{l}\text { Da nau vang Hoang } \\
\text { Su Phi }\end{array}$ & $\begin{array}{l}\text { Hoang Su Phi, Ha } \\
\text { Giang }\end{array}$ & $296 \mathrm{bp}$ & & 800 bp & $100 \mathrm{bp}$ & $280+350 b p$ \\
\hline 12 & Nep vang Mai Chu & Mai Chau, Hoa Binh & 296 bp & 543 bp & $800 \mathrm{bp}$ & $100 \mathrm{bp}$ & $280 \mathrm{bp}$ \\
\hline 13 & Te do Đa Bac & Đa Bac, Hoa Binh & 296 bp & - & - & $100 \mathrm{bp}$ & - \\
\hline 14 & Nep trang Le Loi & $\begin{array}{l}\text { Le Loi, Sin Ho, Lai } \\
\text { Chau }\end{array}$ & $296 \mathrm{bp}$ & - & 800 bp & $144+100$ bp & $280+350 \mathrm{bp}$ \\
\hline 15 & $\begin{array}{l}\text { Nep vang trang } \\
\text { Mien Bac }\end{array}$ & Mien Bac & $296 \mathrm{bp}$ & 543 bp & $800 \mathrm{bp}$ & $144+100$ bp & $280+350 b p$ \\
\hline 16 & Nep vang Pleiku & TX Plei Ku, Gia Lai & 296 bp & - & - & $100 \mathrm{bp}$ & $280 \mathrm{bp}$ \\
\hline 17 & Da do chu se & Chu se, Gia Lai & 296 bp & - & 800 bp & $144+100$ bp & $280 \mathrm{bp}$ \\
\hline 18 & $\begin{array}{l}\text { Nep nau nhat } \\
\text { Krong Pach }\end{array}$ & $\begin{array}{l}\text { Krong Pach, Dac } \\
\text { Lac }\end{array}$ & $296 \mathrm{bp}$ & - & 800 bp & $100 \mathrm{bp}$ & $280 \mathrm{bp}$ \\
\hline 19 & $\begin{array}{l}\text { Da tim nau Krong } \\
\text { Ana }\end{array}$ & Krong Ana, Dac Lac & $296 \mathrm{bp}$ & - & - & $100 \mathrm{bp}$ & $280 \mathrm{bp}$ \\
\hline 20 & $\begin{array}{l}\text { Da vang Krong } \\
\text { Ana }\end{array}$ & Krong Ana, Dac Lac & $296 \mathrm{bp}$ & - & $800 \mathrm{bp}$ & $100 \mathrm{bp}$ & $280 \mathrm{bp}$ \\
\hline 21 & $\begin{array}{l}\text { Ngo vang Lac-Dac } \\
\text { Lac }\end{array}$ & Lac, Dac Lac & $296 \mathrm{bp}$ & - & - & $100 \mathrm{bp}$ & $280 \mathrm{bp}$ \\
\hline 22 & $\begin{array}{l}\text { Ngo nau vang Lac- } \\
\text { Dac Lac }\end{array}$ & Lac, Dac Lac & $296 \mathrm{bp}$ & - & $800 \mathrm{bp}$ & $100 \mathrm{bp}$ & $280 \mathrm{bp}$ \\
\hline
\end{tabular}


The alleles at the 3' end (LcyE-3'TE) and the 5' end (LcyE-5'TE) of LcyE gene were amplified by LcyE-3'TE-F: 5'-ACCCGTACG TCGTTCATCTC-3', LcyE-3'TE-R: 5'-ACC CTGCGTGGTCTCAAC-3' (Azmach et al., 2013) and LcyE-5'TE-F: 5'-AAGCAGGG AGACATTCCAG-3', LcyE-5'TE-R: 5'-GAG AGGGAGACGACGAGACAC-3' primers (Babu et al., 2013), respectively.

\section{Methods}

\section{Amplification of alleles of the crtRB1 and LcyE genes by PCR}

Genome DNA was extracted according to CTAB method of Saghai Maroof et al., (1984). PCR reactions with crtRB1-3'TE-F, crtRB13'TE-R1 and crtRB1-3'TE-R2 primers were conducted as previously reported (Tran Thi Luong, Nguyen Duc Thanh, 2018).

PCR reactions with LcyE-3'TE-F, LcyE3'TE-R and LcyE-5'TE-F, LcyE-5'TE-R primers were performed with a reaction cycle of: $94^{\circ} \mathrm{C}$ for $10 \mathrm{~s}$, followed by 35 cycles $\left(95^{\circ} \mathrm{C}\right.$ for $10 \mathrm{~s}, 58^{\circ} \mathrm{C}$ for $35 \mathrm{~s}$, and $72^{\circ} \mathrm{C} 10 \mathrm{~s}$ (Harjes et al., 2008). PCR products were electrophoresis on $1.5 \%$ agarose gel.

\section{RESULT}

\section{Allelic polymorphism of $\beta$-carotene hydroxylase gene (crtRB1)}

For $c r t R B 1$ gene, allelic polymorphisms at the 3' end (crtRB1-3'TE) and the 5' end (crtRB1-5'TE) were analyzed. The 3'TE polymorphism of crtRBI produces 3 alleles related to variation in $\beta$-carotene content (Yan et al., 2010): allele 1 (543 bp without TE insertion), allele 2 (296 bp $+875 \mathrm{bp}$, with 325 bp TE insertion) and allele 3 (296 bp +1221 bp $+1880 \mathrm{bp}$; with the insertion of $1250 \mathrm{bp}$ TE). Allele 1 is known as a favorable allele for the increase in $\beta$-carotene by reducing the expression of $c r t R B 1$ gene transcription, while allele 2 and allele 3 are unfavorable for the increase in content of $\beta$-carotene. Our results show allelic polymorphism at the 3 ' end of crtRB1 gene: out of 22 traditional maize accessions, there are $5(22.73 \%)$ (Te vang Lung chang 2, Te vang Na Leng, Te vang Lung can, Nep vang Mai Chau, Nep vang trang Mien Bac) have favorable allele (543 $\mathrm{bp)}$ for the increase in $\beta$-carotene (table 1 , Fig. 1), for the remaining accessions, no alleles were amplified. Thus, the proportion of investigated accessions that have allele 1 at the 3' end of crtRB1 genes in traditional maize accessions is quite high compared to the claims of foreign authors (Thirusendura Selvi et al., 2014; Muthusamy et al., 2015; Sagare et al., 2015) and equivalent to those in the imported and improved maize varieties that we previously published (Tran Thi Luong, Nguyen Duc Thanh, 2018).

With the crtRB1-3'TE-F / R1 primer pair (Fig. 2), no favorable alleles were recorded in all investigated maize. There were 3 accessions $(2,13,17)$ without allele amplification, 19 accessions with unfavorable allele 2 (296 bp), of which 2 accessions ( 3 and 8) have an insertion of $325 \mathrm{bp}$.

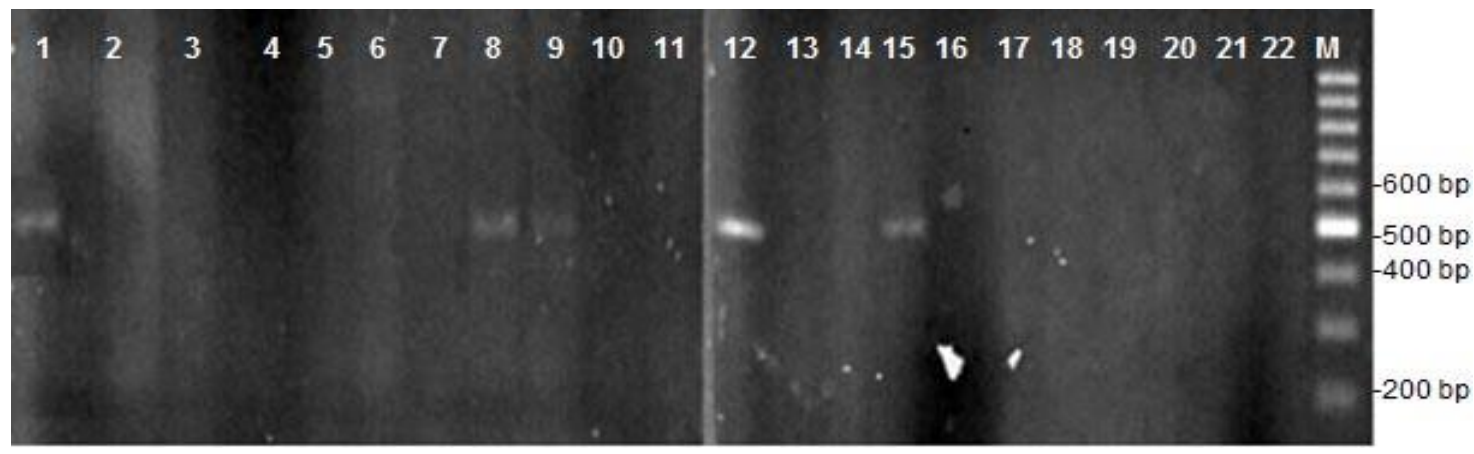

Figure 1. PCR results for alleles at the 3' end of $c r t R B 1$ gene with crtRB1-3'TE-F/R2 primers. M. Marker $100 \mathrm{bp} ; 1-22$ accession numbers as shown in table 1 


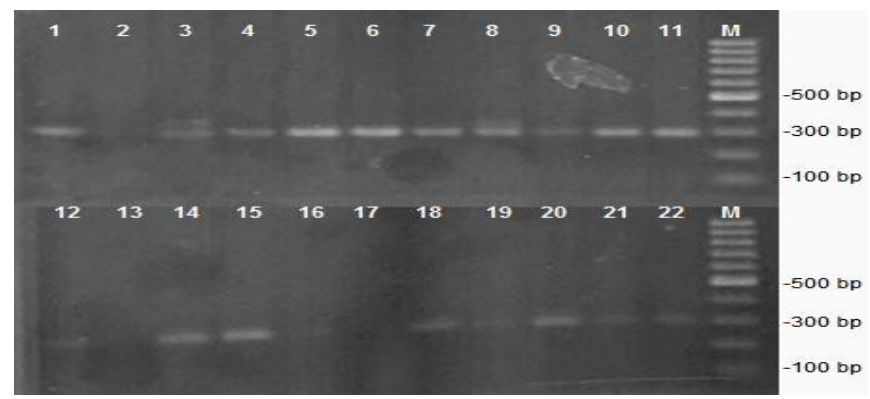

Figure 2. PCR results for alleles at the 3' end of $c r t R B 1$ gene with crtRB1-3'TE-F/R1 primers. M. Marker $100 \mathrm{bp} ; 1-22$ accession numbers as shown in table 1

Allelic polymorphism at the 5'end of CrtRB1 gene is due to the change of 397/206 bp indel (Yan et al., 2010). Allele 2 (600 bp) is favorable allele. The analyses of 22 maize accessions showed that there was polymorphism among the accessions.
However, there were no allele-specific bands for favorable alleles. Fourteen accessions have allele $1(800 \mathrm{bp})$ that is unfavorable (Fig. 3). The remaining accessions do not have specific allele.

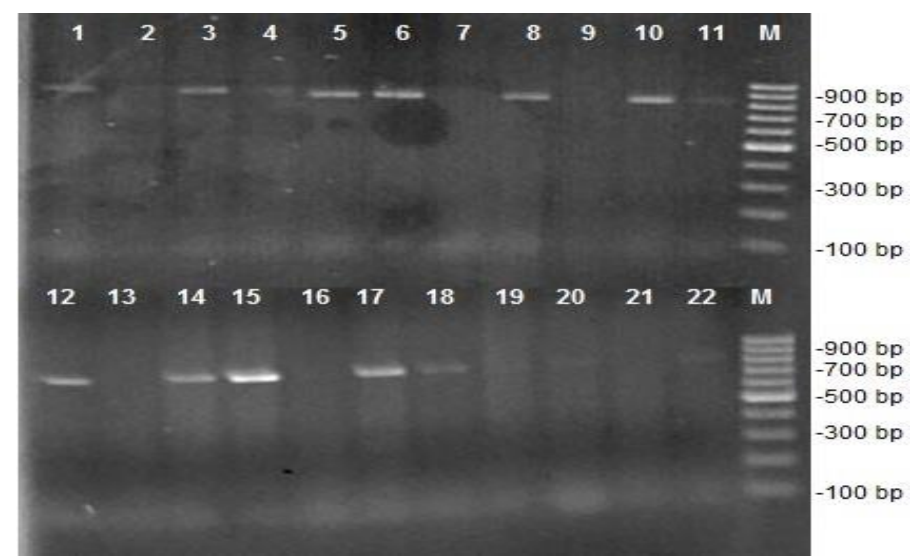

Figure 3. PCR results for alleles at the 5' end of $c r t R B 1$ gene with crtRB1-5'TE-F/R1. M. Marker $100 \mathrm{bp} ; 1-22$ accession numbers as shown in table 1

Allelic polymorphism of Lycopene $E$ gene (LcyE)

According to Harjes et al. (2008), the 3' end of $L c y E$ gene has 2 alleles: Allele1 $(399+$ $502 \mathrm{bp})$ and allele 2 that has $8 \mathrm{bp}$ deletion $(144+502$ bp) affecting the content of $\beta$ carotene. When analyzing 22 maize accessions using LcyE-3'TE-F / R primers, 5 accessions (22.73\%), including Bap cham deng, Bap cham, Nep trang Le Loi, Nep vang trang Mien Bac and Da do chu se possessed allele $2(144 \mathrm{bp})$ affecting the content of $\beta$ carotene (Fig. 4). The remaining 17 accessions have a band of about $100 \mathrm{bp}$, this may be the altered allele 2 that lost $44 \mathrm{bp}$.

Allele polymorphism at the 5' end LcyE5'TE was analyzed by LcyE-5' TE-F / R primers. With this pair of primers, 4 alleles can be amplified, in which allele1 (150 bp + $280 \mathrm{bp}$ ) and allele 4 (933 bp) are favorable for the accumulation of $\beta$-carotene, and allele 2 $(250 \mathrm{bp})$ and allele $3(250 \mathrm{bp}+380 \mathrm{bp})$ are unfavorable (Harjes et al., 2008).

The results in tables 1 and figure 5 show that in the 22 traditional maize accessions, there were polymorphisms among the 
accessions, but there are no accessions that carry favorable alleles. There were 21 accessions having the band of about $280 \mathrm{bp}$, including 6 accessions that have the bands of $280 \mathrm{bp}$ and $350 \mathrm{bp}$, this may be a variation in allele 2 (250 to $280 \mathrm{bp})$ and allele $3(250+$ $380 \mathrm{bp}$ to $280+350 \mathrm{bp})$. In one accession (13- Te Do, Da Bac), no alleles were amplified.

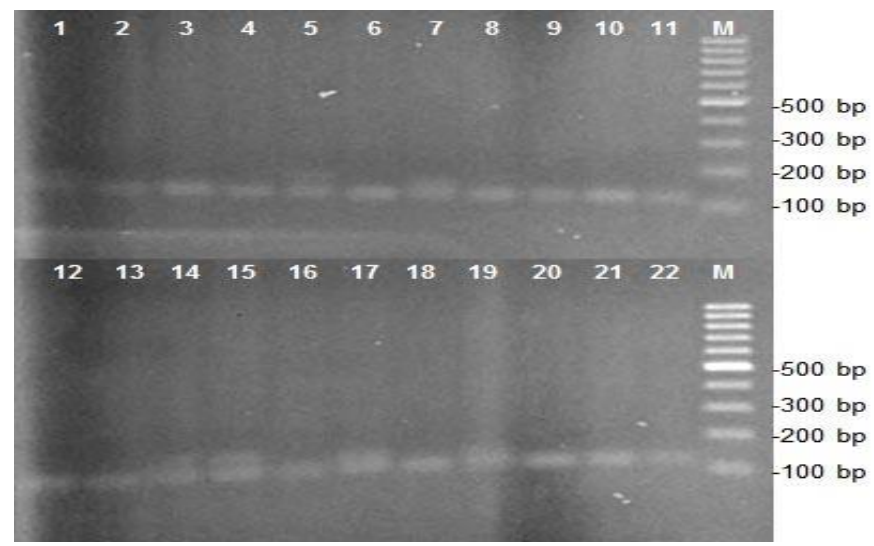

Figure 4. PCR results for alleles at the 3'end of $L c y E$ with LcyE-3'TE-F/R primers. M: Marker $100 \mathrm{bp} ; 1-22$ accession numbers as shown in table 1

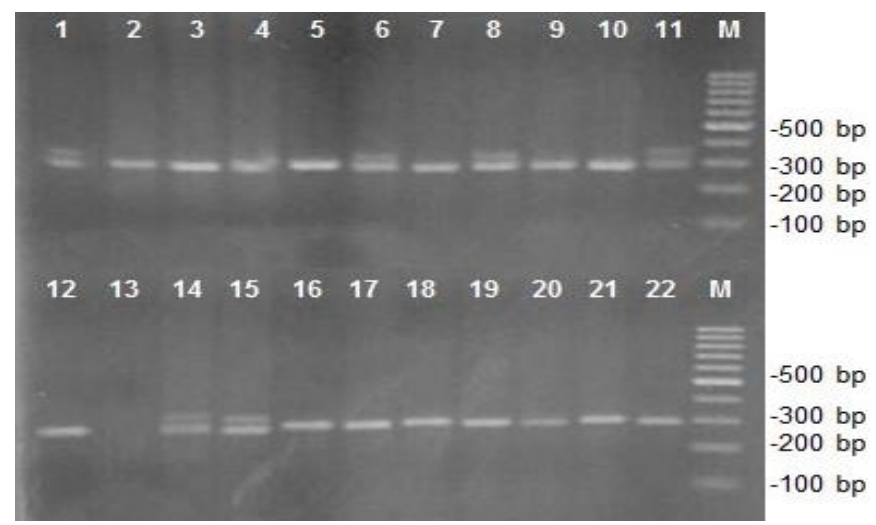

Figure 5. PCR results for alleles at the 5' end of LcyE with LcyE-5'TE-F/R primers. M: Marker $100 \mathrm{bp}$; accession numbers as shown in table 1

Thus, there were no accessions among investigated maize accessions that have favorable alleles for increasing the $\beta$-carotene at the 5' end of the $L c y E$ gene, while there were 5 accessions have the favorable alleles at the 3' end of $L c y E$.

\section{CONCLUSION}

The results of the study on allelic polymorphism related to the $\beta$-carotene content of crtRBI and LcyE genes in the group of 22 Vietnamese traditional maize accessions show that there are alleles polymorphisms at the $3^{\prime}$ and $5^{\prime}$ ends of crtRB 1 and $L c y E$ genes. The proportion of favorable alleles related to $\beta$-carotene levels at the 3 ' end of $\operatorname{crtRB} 1$ is quite high $(5 / 22=$ $22.73 \%$ ). Similar results were obtained for alleles at the 3' end (LcyE-3'TE) of the $L c y E$ gene. The five accessions have favorable allele at the 3' end of crtRBl genes, including: Te vang Lung chang 2 , Te vang $\mathrm{Na}$ Leng, Te vang Lung can, Nep vang Mai Chau, Nep vang trang Mien Bac, and the five 
accessions: Bap cham deng, Bap cham, Nep trang Le Loi, Nep vang trang Mien Bac and Da do chu se possessed the favorable alleles at the 3' end of LcyE5 gene. Interestingly, accession Nep vang trang mien Bac has favorable alleles at the 3' end of both crtRBI and $L c y E$ genes. While all investigated accessions did not carry any favorable alleles at the 5' end of crtRBI and $L c y E$ genes. The identification of local traditional maize accessions that carry favorable alleles related to $\beta$-carotene content opens up the potential of exploiting indigenous genetic resources for genetic research as well as the creation of maize varieties with high $\beta$-carotene content.

Acknowledgments: The work was carried out in the framework of the Program to support scientific research activities for senior researcher in 2019 by the Vietnam Academy of Science and Technology, Code: NCVCC08.05/19-19.

\section{REFERENCES}

Azmach G., Gedil M., Menkir A., Spillane C., 2013. Marker-trait association analysis of functional gene markers for provitamin A levels across diverse tropical yellow maize inbred lines. BMC Plant Biology, 13: 227.

Babu R., Rojas N. P., Gao S., Yan J., Pixley K., 2013. Validation of the effects of molecular marker polymorphisms in $L c y E$ and $c r t R B 1$ on provitamin A concentrations for 26 tropical maize populations. Theor. Appl. Genet., 126: 389-399.

Fu Z. Y., Chai Y. C., Zhou Y., Yang X. H., Warburton M. L., Xu S. T., Cai Y., Zhang D. L., Li J. S., Yan J. B., 2013a. Natural variation in the sequence of PSY1 and frequency of favorable polymorphisms among tropical and temperate maize germplasm. Theor. Appl. Genet., 126: 923-935.

Fu J. J., Cheng Y. B., Linghu J., Yang X. H., Kang L., Zhang Z. X., Zhang J., He C., Du X. M., Peng Z. Y., Wang B., Zhai L. H., Dai C. M., Xu J. B., Wang W. D., Li X. R., Zheng J., Chen L., Luo L. H., Liu J. J., Qian X. J., Yan J. B., Wang J., Wang
G. Y., 2013b. RNA sequencing reveals the complex regulatory network in the maize kernel. Nat. Commun., 4: 2832.

Harjes C. E., Rocheford T. R., Bai L., Brutnell T. P., Kandianis C. B., Sowinski S. G., Buckler E. S., 2008. Natural genetic variation in lycopene epsilon cyclase tapped for maize biofortification. Science, 319: 330-333.

Huang Z., Liu Y., Qi G., Brand D., Zheng S. G., 2018. Role of vitamin A in the immune system. J. Clin. Med., 7(9): 258.

Kurilich A. C., Juvik J. A., 1999. Quantification of carotenoid and tocopherol antioxidants in Zea mays. $J$ Agric Food Chem., 47: 1948-1955.

Tran Thi Luong, Nguyen Duc Thanh, 2018. Investigating the frequency of alleles of crtRBI and LcyE genes that are favorable for $\beta$-carotene accumulation in some maize line cultivated in Vietnam. Tap chi Sinh hoc, 40 (2): 244-251.

Muthusamy V., Hossain F., Thirunavukkarasu N., Saha S., Gupta1 H.S., 2015. Allelic variations for lycopene- $\varepsilon$-cyclase and $\beta$ carotene hydroxylase genes in maize inbreds and their utilization in $\beta$-carotene enrichment program. Cogent Food \& Agriculture, 1: 1033141, https://dx.doi.org/10.1080/23311932.201. 1033141.

Ross D. A., 1998. Vitamin A and public health: Challenges for the next decade. Proc. Nutrition Society, 57: 159-165.

Saghai-Maroof M. A., Soliman K. M., Jorgensen R. A., Allard R. W., 1984. Ribosomal DNA spacer-length polymorphisms in barley: Mendelian inheritance, chromosomal location, and population dynamics. Proc Natl Acad Sci USA, 81: 8014-8018.

Selvi T. D., Senthil N., Yuvaraj A., John Joel A., Mahalingam A., Nagarajan P., Vellaikumar S., Srimathi P., Raveendran M., Nepolean T., 2014. Assessment of crtRB1 Polymorphism Associated with 
Increased $\beta$-Carotene Content in Maize (Zea mays L.) Seeds, Food Biotechnol., 28: 41-49.

Semba R. D., 1994. Vitamin A, immunity, and infection. Clinical Infectious Diseases, 19(3): 489-499.

Tanumihardjo S. A., Russel R. M., Stephensen C. B., Gannon B. M., Craft N. E., Haskell M. J., Lietz G., Schulze K., Raiten D. J., 2016. Biomarkers of nutrition for development (BOND) vitamin A review. J Nutr., 146: 1816S1848S.

Vallabhaneni R., Wurtzel E. T., 2009. Timing and biosynthetic potential for carotenoid accumulation in genetically diverse germplasm of maize. Plant Physiol., 150: 562-572.

World Health Organization, 2010. World health statistics. Geneva, Switzerland: WHO.

Yan J., Bermudez-Kandianis C. B., Harjes C. E., Bai L., Kim E., Yang X., Skinner D.,
Fu Z., Mitchell S., Li Q., Salas-Fernandez M., Zaharieva M., Babu R., Fu Y., Palacios N., Li J., Della Penna D., Brutnell T., Buckler E., Warburton M., Rocherford T., 2010. Rare genetic variation at Zea mays crtRB1 increases $\beta$ carotene in maize grain. Nat Genet., 42:322-327.

Zhou Y., Han Y., Li Z., Fu Y., Fu Z., Xu S., Li J., Yan J., Yang X., 2012. ZmcrtRB3 encodes a carotenoid hydroxylase that affects the accumulation of $\alpha$-carotene in maize kernel. J Integrative Plant Biol., 54(4): 260-269.

Zunjare R. U., Hossain F., Muthusamy V., Baveja A., Chauhan H. S., Thirunavukkarasu N., Saha S., Gupta H. S., 2017. Influence of rare alleles of $\beta$ carotene hydroxylase and lycopene epsilon cyclase genes on accumulation of provitamin A carotenoids in maize kernels. Plant Breed, 136(6): 872-880. 